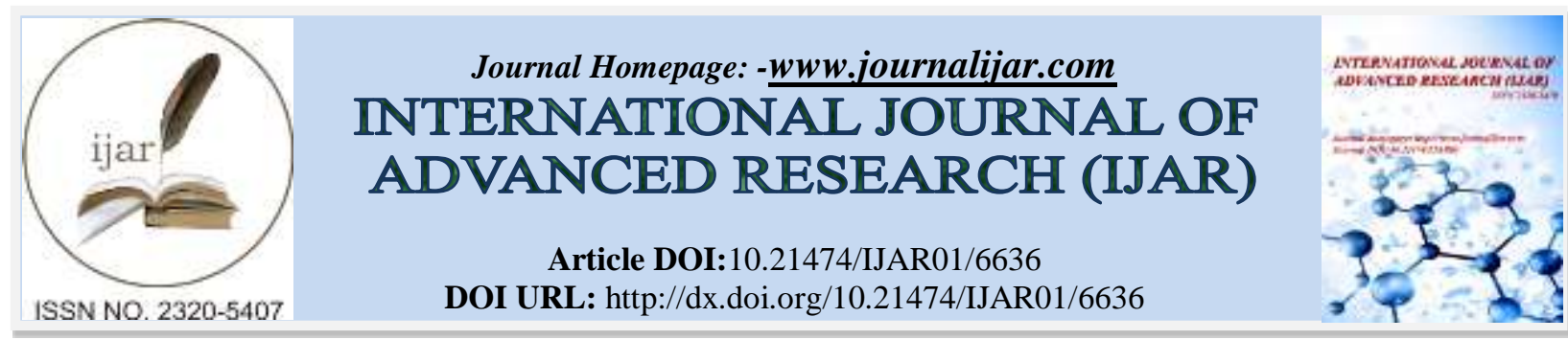

RESEARCH ARTICLE

\title{
ASSESSMENT OF AORTIC VALVE SCLEROSIS AS A MARKER OF CORONARY ARTERY DISEASE AND ITS RISK FACTORS.
}

\section{Dr. Suresh V Patted ${ }^{1}$, Dr. Sanjay C Porwal ${ }^{2}$, Dr. Sameer Ambar ${ }^{3}$, Dr. M R Prasad ${ }^{3}$, Dr. Suhasini.Atharga ${ }^{4}$, Dr.} Vishwanath Hesarur ${ }^{5}$, Dr. Vaibhav Patil ${ }^{5}$ and Dr. Nikhil. $\mathbf{B}^{4}$.

1. Professor and HOD, Department of Cardiology, J. N. Medical College, Belgaum, Karnataka, India.

2. Professor, Department of Cardiology, J. N. Medical College, Belgaum, Karnataka, India.

3. Associate Professor, Department of Cardiology, J. N. Medical College, Belgaum, Karnataka, India.

4. Senior Resident, Department of Cardiology J. N. Medical College, Belgaum, Karnataka, India.

5. Assistant Professor, Department of Cardiology, J. N. Medical College, Belgaum, Karnataka, India.

\section{Manuscript Info}

(.........................

Manuscript History

Received: 25 December 2017

Final Accepted: 27 January 2018

Published: February 2018

Keywords:-

AVS: Aortic valve sclerosis CAD: Coronary artery disease.

\section{Abstract}

Introdution: Aortic valve sclerosis is defined as calcification of the aortic leaflets without impairment in leaflet excursion or antegrade velocity across the valve $<2.5 \mathrm{~m} / \mathrm{s}$. It is characterized by a gradual progression beginning with calcium deposition that may ultimately transform to aortic stenosis (AS) with obstruction of outflow from the left ventricle. Aortic valve sclerosis (AVS) presence is associated with an increase in cardiovascular mortality and morbidity.

Aims \& Objective: The aim of this study is to investigate the association between presence of AVS with occurrence of coronary artery disease and classical risk factors.

Materials and Methods: The relationship among aortic sclerosis, the presence and acuity of CAD and cardiovascular outcomes in patients presenting with chest pain was studied by prospective follow-up of a cohort of patients from an observational cross-sectional study.

A total of 275 Patients were enrolled for the study and all the patients underwent transthoracic echocardiography and diagnostic coronary angiography to assess AVS and to evaluate the extent of coronary artery involvement respectively.

Results: Elderly patients aged $>60$ years with aortic valve sclerosis had higher prevalence of obstructive coronary artery disease with $\mathrm{p}$ value of $<0.05 \&$ AVS is considered as independent predictor of obstructive CAD.

Conclusion: Our study concludes that AVS is strongly associated with the extent of coronary artery disease and that echocardiographic detection of AVS in patients undergoing coronary angiography may be considered as a new surrogate marker for the extent of coronary atherosclerosis and thereof CAD.

Copy Right, IJAR, 2018,. All rights reserved. 


\section{Introduction:-}

Aortic valve sclerosis (AVS) is defined as a progressive calcification, increased thickening of aortic valve leaflets without valve obstruction and ante grade velocity across the valve less than $2.5 \mathrm{~m} / \mathrm{s}^{1}$.AVS presence is associated with an approximately $50 \%$ increase in cardiovascular mortality and morbidity ${ }^{2}$. Increased prevalence of obstructive coronary lesions and triple vessel coronary artery disease (CAD) has been shown in patients with AVS, but the data till date are limited ${ }^{3,4}$. It has been reported that CAD is associated with increased carotid intima-media thickness, presence of atherosclerotic plaques in aorta, presence of calcifications in mitral ring, and lower limb atherosclerosis ${ }^{5}$. AVS predictive value among cardiovascular findings in these patients is limited. Echocardiography scanning of individuals without CAD symptoms is cost-prohibitive, so finding existing subgroups of cases with AVS at a high risk for heart disease was necessary. Over the last decade, different studies evaluated the relationship between AVS and CAD, but research about AVS's importance as a single factor in classification of risk is limited. AVS was also documented as a strong predictor of obstructive CAD and it might be considered in CAD risk stratification $^{7}$. Thus, the determination of the degree of AVS is the most imperative risk for CAD and should be investigated. The purpose of this study was to evaluate whether the presence and severity of AVS in echocardiographic evaluation could be used as a predictor for obstructive CAD severity. The extent of CAD in patients hospitalized for chest pain is of concern given the number and vital importance of the involved coronary vessels. We are looking to investigate the special implication in risk acceptance for patients who have had a moderate risk for CAD.

\section{Methods:-}

\section{Study population:-}

This cross-sectional study included 275 patients with chest pain who were clinically suspected cases of CAD and scheduled for coronary angiography between October 2015 to September 2017 in JN Medical college ,Department of cardiology KLE University Hospital, Belagavi, India. Clinical history and laboratory data were collected from all patients. All patients underwent complete transthoracic echocardiography (TTE) prior to considering coronary angiography either on the same day or within 2 days of the procedure. Inclusion criteria was first elective diagnostic coronary angiography and a normal aortic valve on fluoroscopy. Patients with aortic stenosis, aortic regurgitation more than mild, rheumatic valvular heart disease, congenital heart disease, history of prosthetic valve replacement were excluded from the study. An informed consent form was obtained from all patients. All procedures were approved by ethical committee JN medical college.

\section{Clinical data:-}

All patients' demographic characteristics and risk factors were determined before they underwent coronary angiography. Diabetes mellitus, systemic hypertension, hyperlipidemia and renal failure were defined as hyperglycemia $\geq 126 \mathrm{mg} / \mathrm{dl}$ fasting blood sugar or on anti-hyperglycaemic medications, blood pressure $\geq 140 / 90$ $\mathrm{mmHg}$ or on antihypertensive medications, LDL $>110 \mathrm{mg} / \mathrm{dl}$ and total cholesterol level $>200 \mathrm{mg} / \mathrm{dl}$, and creatinine more than $1.3 \mathrm{mg} / \mathrm{dl}$, respectively. Smoking was defined as active smoking within the past 12 months.

Electrocardiographic (ECG) changes including ischemic ST-T changes, presence of Q-wave, bundle branch block and arrhythmias were evaluated.

\section{Echocardiographic Evaluation:-}

Complete TTE studies were performed according to the recent ASE-AHA guidelines for all patients using commercially available system EPIQ 7C Philips machine in supine and left lateral positions using X5-1 transducer. Two dimensional assessments of the aortic valve were made from the parasternal long axis, short axis and apical views with appropriate gain settings. Peak transaortic flow velocity was measured from the apical view by continuous wave Doppler. AVS was defined as a focal area of increased echogenicity and thickening of the aortic valve leaflets without restriction of leaflet motion and a transaortic flow velocity $<2.5 \mathrm{~m} / \mathrm{s}$ on TTE ${ }^{2,7}$. The thickness of sclerotic aortic cusps were determined from the end diastolic frozen echocardiographic images obtained in either short or long axis. Mild, moderate and severe AVS were classified as cusp thickness 2-3.9 mm, 4-6 mm and >6 mm, respectively ${ }^{8,9}$.

\section{Coronary angiography:-}

Coronary angiography in multiple views was performed according Judkins or Sones Standard technique ${ }^{10}$. At least four views for evaluation of left main (LM) coronary artery, left anterior descending (LAD), left circumflex (LCX) and right coronary artery (RCA) were performed. Angiographic results were interpreted by angiographer who was 
blinded to echocardiographic findings. Significant CAD was defined as more than $50 \%$ reduction of internal diameter of at least one coronary artery. The definition of 1-, 2- or 3- vessel disease was based on the criteria of Coronary Artery Surgery study ${ }^{11}$.

\section{Results:-}

A total of 275 patients who met the inclusion criteria were enrolled in the study. The population with age of $>60$ years were 201 which comprised of $73.09 \%$ \& <60 years were 74 which comprised of $26.91 \%$. Females 85 (30.91\%) and Males 190 (69.01\%) comprised of the study population. Graph 1. Shows Age wise distribution of study population with AVS.

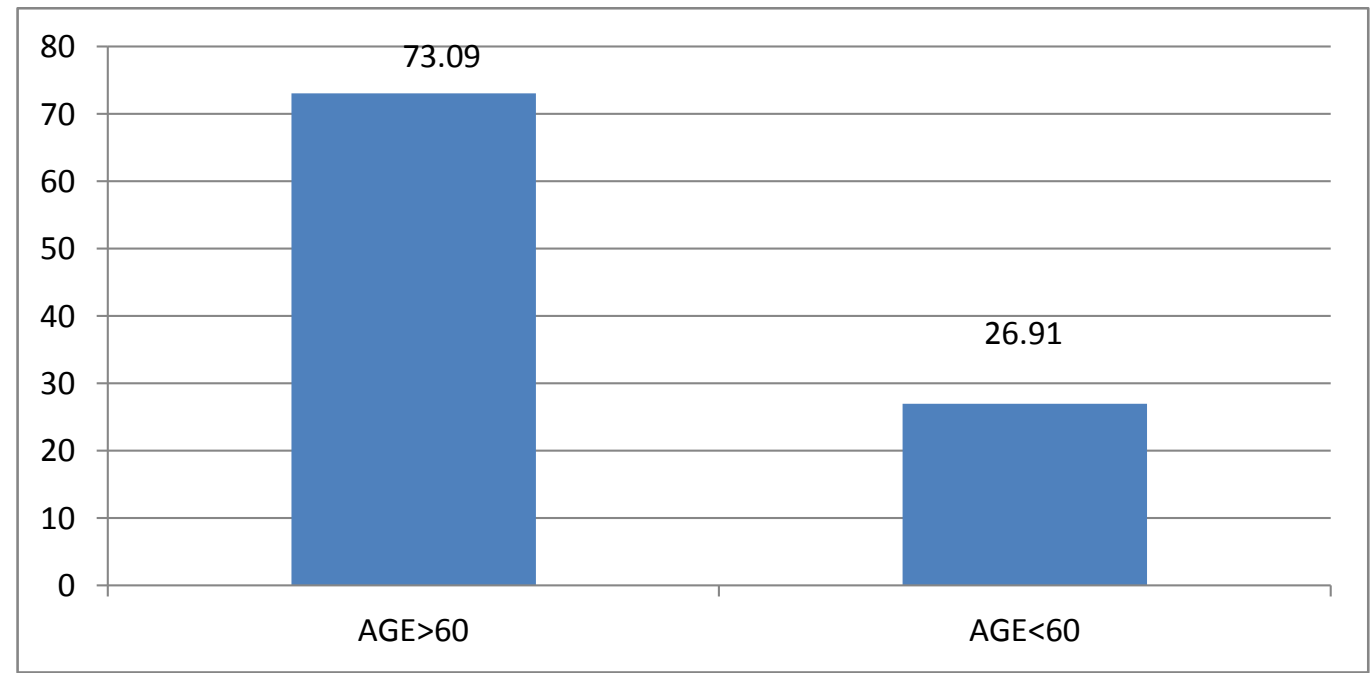

Graph 1:- Age wise Distribution of patients with AVS.

\section{Gender wise distribution:-}

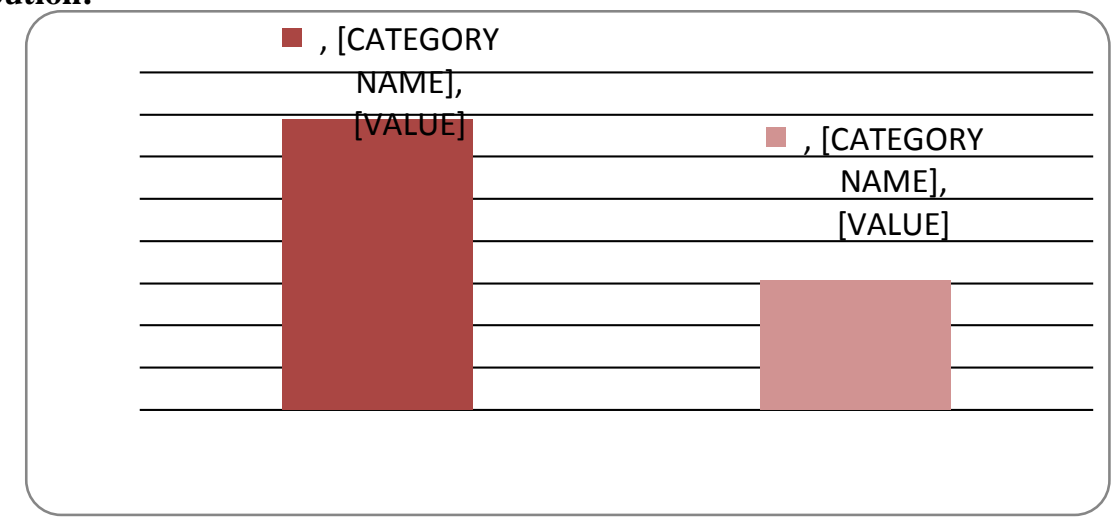

Graph 2:- Gender Wise Distribution

Among 275 patients $69.09 \%$ were male \& $30.91 \%$ were female. Patients with diabetes were $193(701.18 \%), \&$ with hypertension were $93(33.82 \%)$ dyslipedemia were $23(8.36 \%)$ \& smoking $38(13.82 \%)$ respectively.

Table 1:-Baseline characteristics of AVS patients with and without CAD

\begin{tabular}{|l|c|c|c|c|c|c|c|}
\hline Characteristics & No CAD & \% & CAD & \% & Total & \% & p-value \\
\hline Age $>=60 y r s$ & 38 & 18.91 & 163 & 81.09 & 201 & 73.09 & $0.0001^{*}$ \\
\hline HTN & 30 & 32.26 & 63 & 67.74 & 93 & 33.82 & 0.0640 \\
\hline DM & 43 & 22.28 & 150 & 77.72 & 193 & 70.18 & 0.0640 \\
\hline SMOKING & 9 & 23.68 & 29 & 76.32 & 38 & 13.82 & 0.7870 \\
\hline DYSLIPIDEMIA & 5 & 21.74 & 18 & 78.26 & 23 & 8.36 & 0.6690 \\
\hline *p $<0.05$
\end{tabular}


Comparing clinical characteristics of patients with and without CAD, age $>60$ years was significantly associated with coronary artery disease among AVS patients with $\mathrm{p}<0.0001 *$.

Among the coronary vessels involved, LAD was most commonly affected and was statistically significant ( $\mathrm{p}<$ $0.001)$.

Table 2:- Distribution of coronary artery involvement:

\begin{tabular}{|l|l|l|}
\hline $\begin{array}{l}\text { Coronary Vessel } \\
\text { Involved }\end{array}$ & $\mathrm{N}$ & P Value \\
\hline LAD & 175 & $0.001^{*}$ \\
\hline LCX & 108 & $>0.5$ \\
\hline RCA & 83 & $>0.5$ \\
\hline SVD & 93 & $>0.5$ \\
\hline DVD & 65 & $>0.5$ \\
\hline TVD & 50 & $>0.5$ \\
\hline
\end{tabular}

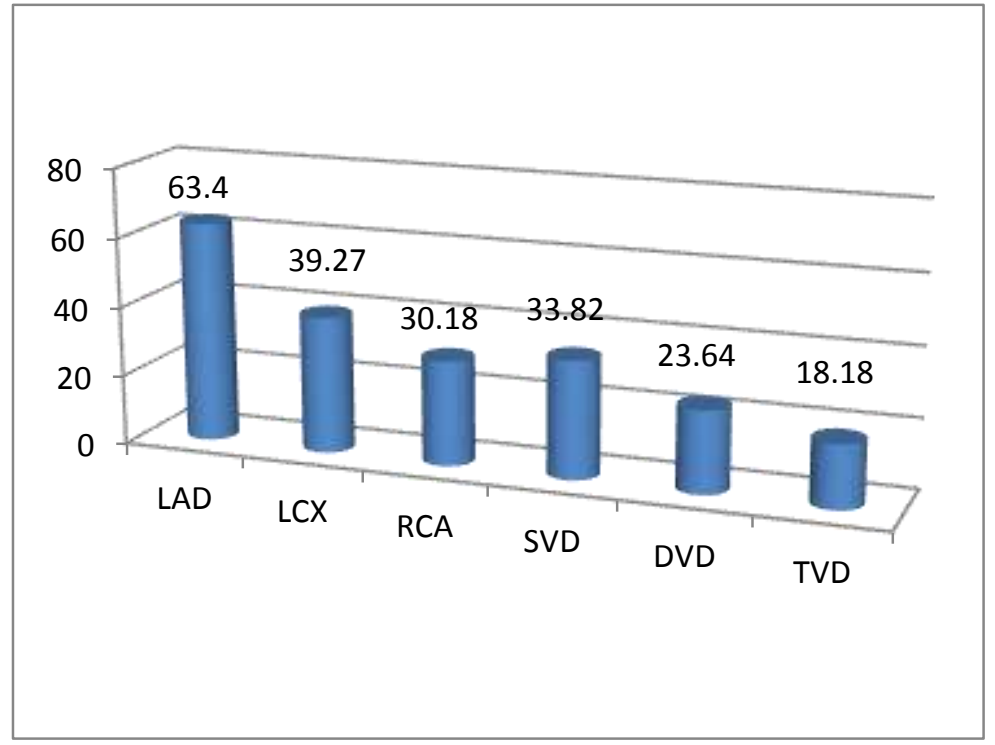

Graph 3:- Distribution of coronary artery involvement.

Table 3:- Multiple logistic regression analysis of CAD by different characteristic

\begin{tabular}{|l|l|l|c|c|c|c|c|}
\hline \multicolumn{2}{|l|}{ Characteristics } & $\%$ & Unadjusted OR & Adjusted OR & \multicolumn{2}{c|}{$95 \%$ CI for OR } & P-value \\
\hline \multirow{2}{*}{ AGE } & $<60 \mathrm{yrs}$ & 56.76 & Ref. & & & & \\
\cline { 2 - 8 } & $>60 \mathrm{yrs}$ & 81.09 & 3.2680 & 3.1510 & 1.7230 & 5.7630 & $0.0001^{*}$ \\
\hline \multirow{2}{*}{ HENDER } & MALE & 67.06 & Ref. & & & & \\
\cline { 2 - 8 } & FEMALE & 77.89 & 1.7310 & 2.0220 & 1.1040 & 3.7030 & $0.0230^{*}$ \\
\hline & NO & 78.02 & Ref. & & & & \\
\cline { 2 - 8 } & YES & 67.74 & 0.5920 & 0.6330 & 0.3480 & 1.1490 & 0.1330 \\
\hline \multirow{2}{*}{ DM } & NO & 67.07 & Ref. & & & & \\
\hline & YES & 77.72 & 1.7120 & 1.6300 & 0.8790 & 3.0230 & 0.1210 \\
\hline \multirow{2}{*}{ DYSLP } & NO & 74.26 & Ref. & & & & \\
& YES & 76.32 & 1.1170 & 1.5250 & 0.6330 & 3.6740 & 0.3460 \\
\hline & NO & 74.21 & Ref. & & & & \\
\cline { 2 - 8 } & YES & 78.26 & 1.2510 & 1.4970 & 0.5010 & 4.4740 & 0.4710 \\
\hline
\end{tabular}




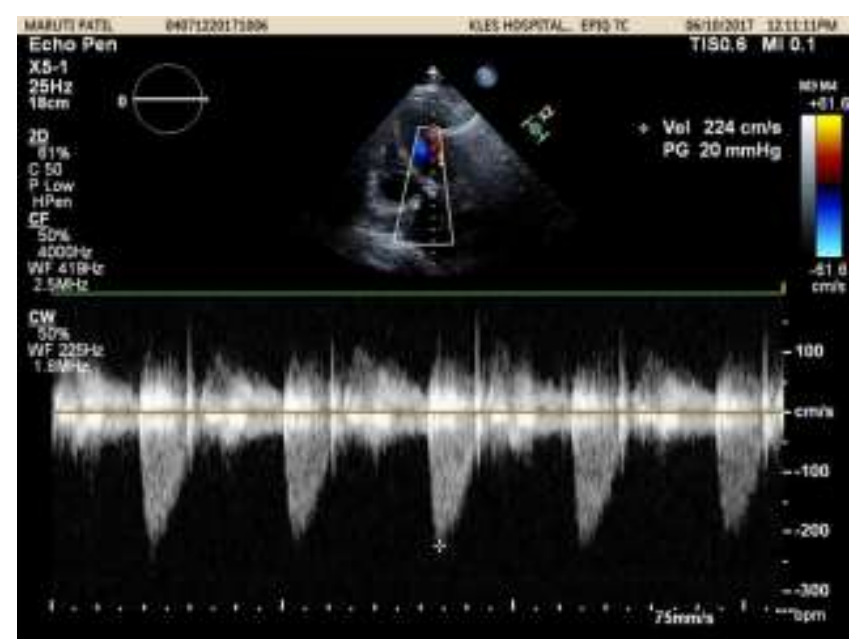

Figure 1:- Peak transaortic flow velocity by continuous wave Doppler

\section{Discussion:-}

In this study, our results revealed that Echocardiographic evidence of AVS is strongly associated with coronary artery disease in individuals who underwent coronary angiography for cardiac evaluation. Our study demonstrates an increase in the prevalence of AVS with ageing, especially in patients >60yrs. AVS has been consistently linked with age and is considered a marker of senile degenerative changes resulting from hemodynamic stress in heart ${ }^{10,11,12,13}$. In a study of 160 patients, Soydinc et al found that AVS was associated with the presence of triple vessel CAD and was independently associated with Gensini score ${ }^{13}$. A study of 230 patients from Fazlinezhad et al found AVS to be an independent predictor of obstructive coronary disease ${ }^{12}$. In 2002, Kirsten and his colleagues studied the morphologic classification system for AVS by transesophageal echocardiography and correlated the subtypes of AVS with the presence of cardiovascular disease, and they concluded that it is possible to identify a subgroup of patients with mixed nodular and diffuse sclerosis, were at increased risk for CAD including multivessel disease $^{14}$. In 2006, Serdar et al ${ }^{15}$, studied the association between AVS and the extent of coronary atherosclerosis by means of the Gensini score system, and he concluded that AVS is strongly interrelated with the coronary angiographic results. Echocardiographic detection of AVS in patients undergoing coronary angiography can predict the extent of coronary atherosclerosis ${ }^{15}$. Another study concluded that pathologic processes that may occur in coronary arteries may be identified more easily in the aortic valve and they suggest that once the diagnosis of AVS has been made by echocardiography, it should be considered as a potential marker of CAD, and patients who are diagnosed with AVS should undergo intensive screening for CAD with aggressive management for modifiable risk factors.

In our study, clinical factors associated with AVS \& CAD pathogenesis includes age, sex, hypertension, hyperlipidemia, diabetes mellitus and smoking. Among these only age was significantly associated with AVS \& CAD with $p$ value of $<0.001$ and the other variables were statistically not significant.

Our study showed extent of coronary artery involvement LAD 63.4\% (with significant p value), LCX 39.27\%, RCA $30.18 \%$ \& involvement of SVD $33.82 \%$,DVD \& TVD $23.64 \% 18.18 \%$ respectively. None of the other studies have shown the extent of specific coronary vessels involvement.

\section{Conclusion:-}

This study predicts that AVS acts as a marker for degenerative process in the heart and also increased prevalence of AVS in HTN, Diabetes, Hyperlipidemia is mainly due to the ageing process. And our study concludes that AVS is strongly associated with the extent of coronary artery involvement and that echocardiographic detection of AVS in patients undergoing coronary angiography may be considered as a new surrogate marker for the extent of coronary atherosclerosis and there of CAD. 


\section{References:-}

1. Otto CM. Why is aortic sclerosis associated with adverse clinical outcomes? J Am CollCardiol 2004; 43: 176-8.

2. Otto CM, Lind BK, Kitzman DW, Gersh BJ, Siscovick DS. Association of aortic valve sclerosis with cardiovascular mortality in the elderly.N Engl J Med 1999; 341:142-7.

3. Fazlinezhad A, Leila Hosseini L, Yousefzadeh H, et al. Correlation between aortic valve sclerosis and coronary artery disease: a cross e sectional study. J Cardio-Thoracic Med. 2013;1:20e25

4. Soydinc S, Davutoglu V, Dundar A, et al. Relationship between aortic valve sclerosis and the extent of coronary artery disease in patients undergoing diagnostic coronary angiography. Cardiology. 2006;106:277e282.

5. Belhassen L, Carville C, Pelle G, Monin JL, Teiger E, Duval-Moulin AM, et al. Evaluation of carotid artery and aortic intima-media thickness measurements for exclusion of significant coronary atherosclerosis in patients scheduled for hea valve surgery. J Am Coll Cardiol 2002; 39:1139-44.

6. Conte L, Rossi A, Cicoira M, Bonapace S, Amado EA, Golia G, et al. Aortic valve sclerosis: a marker of significant obstructive coronary artery disease in patients with chest pain? J Am SocEchocardiogr 2007; 20: 703-8

7. Tolstrup K, Crawford MH, Roldan CA.Morphologic characteristics of aortic valve sclerosis by transesophageal echocardiography: importance for the prediction of coronary artery disease. Cardiol 2002; 98: 154-8

8. Tolstrup K, Roldan CA, Qualls CR, Crawford MH. Aortic valve sclerosis, mitral annular calcium, and aortic root sclerosis as markers of atherosclerosis in men.Am J Cardiol 2002; 89: 1030-4.

9. Chandra HR, Goldstein JA, Choudhary N, O'Neill CS, George PB, Gangasani SR, et al. Adverse outcome in aortic sclerosis is associated with coronary artery disease and inflammation. J Am CollCardiol. 2004; 43: 169 75 .

10. Otto CM, Kuusisto J, Reichenbach DD, et al. Characterization of the early lesion of 'degenerative' valvular aortic stenosis Histological and immunohistochemical studies. Circulation. 1994;90:844e853.

11. 0. Rossi A, Targher G, Zoppini G, et al. Aortic and mitral annular calcifications are predictive of all-cause and cardiovascular mortality in patients with type 2 diabetes. Diabetes Care. 2012;35:1781e1786.

12. . Soydinc S, Davutoglu V, Dundar A, et al. Relationship between aortic valve sclerosis and the extent of coronary artery disease in patients undergoing diagnostic coronary angiography. Cardiology. 2006;106:277e282

13. Head SJ, Farooq V, Serruys PW, et al. The SYNTAX score and its clinical implications. Heart. 2014;100:169e1

14. . Tolstrup K, Crawford M, Roldan CA (2002) Morphologic Characteristics of Aortic Valve Sclerosis by Transesophageal Echocardiography: Importance for the prediction of coronary artery disease cardiology98(3):154-158.

15. Prasad Y, Bhalodkar NC (2004) Aortic sclerosis - a marker of coronary atherosclerosis.Clin cardiol 27(12):671673. 